DOI: $10.20472 / T E .2020 .8 .1 .002$

\title{
PROFESSIONALISM IS PRIORITY FOR MACAO CLINICAL NURSING STUDENTS: FOCUSED ETHNOGRAPHY OF PRECEPTORS
}

\author{
CINDY SIN U LEONG, LYNN B. CLUTTER
}

\begin{abstract}
:
Clinical preceptors are primary mentors as well as important role models for nursing students who are learning skills, knowledge and critical decision-making in clinical practice. However, little is known about how the preceptors perceive nursing students during their practicum in a Chinese society. The study used a focused ethnography to explore clinical preceptor perceptions of nursing student performance in professional attitudes, knowledge, theory, and nursing skills. The preceptors were from critical-care, surgical, and medical units of hospitals, health-care centers, and nursing homes. Twenty clinical preceptors participated in 30-60 minute interviews that were transcribed and analyzed. One principal theme that emerged from the study was the need for greater professionalism. The nursing professional demeanor of students theme includes subthemes of active behaviors, having "heart" or attitude intent to learn to do the work of nursing, and demonstrating a professional image. If nursing students show these attributes during clinical experiences, it was believed that all other learning would take place easily. Academic educators and clinical preceptors are in the best position to foster student development and expressions of professionalism.
\end{abstract}

\section{Keywords:}

professionalism, clinical preceptors, nursing students

JEL Classification: 100, I19, 123

\section{Authors:}

CINDY SIN U LEONG, Macao Polytechnic Institute, Macau, Email: suleong@ipm.edu.mo LYNN B. CLUTTER, School of Nursing, The University of Tulsa, United States, Email: lynn-clutter@utulsa.edu

\section{Citation:}

CINDY SIN U LEONG, LYNN B. CLUTTER (2020). Professionalism is Priority for Macao Clinical Nursing Students: Focused Ethnography of Preceptors. International Journal of Teaching and Education, Vol. VIII(1), pp. 11-32., 10.20472/TE.2020.8.1.002 


\section{Introduction}

Clinical practice is a critical aspect of nursing education (Benner, Sutphen, Leonard, \& Day, 2009). To graduate, nursing students need to fulfill many clinical hours in various clinical areas. Practice-based clinical education makes use of the knowledge and theory learned in lecture (Henderson \& Tyler, 2011). Through clinical practice, nursing students can develop professional attitudes, nursing skills, decision making and critical thinking in real-world situations (Botti \& Reeve, 2003; Hickey, 2010; Megel, Nelson, Black, Vogel, \& Uphoff, 2013). It is expected that nursing students will learn much of the professional practice and the responsibilities of being a staff nurse through hands-on practice (Kragelund, 2011; Wolff et al., 2010). The importance of clinical practice also applies in a university based nursing program in Macao, located in southern China.

Since the $21^{\text {st }}$ century a higher diploma nursing training programme has existed in Macao, a special administrative region of China (Leong, Xing, \& Wong, 2013). The bachelor degree of nursing program, successfully introduced in 2009, consists of 4 years and is in an academic setting. Beginning in 2012, all nursing students in Macao graduated with bachelor's degrees. In the particular program, there are clinical placements in all semesters of the 4 years courses. The curriculum includes considerable emphasis on clinical practice along with the knowledge and theory lectures. The required core courses are similar in content to those in BSN programs in the western world.

Macao is one of the most densely populated cities in the world, with 660,000 residents in $31 \mathrm{~km}^{2}$ in size. It is located in the most southern part of mainland China. Even though, the ratio of staff nurse to region residents is 1:321 in Macao, the life expectancy averages 84 years old for residents (Health Statistics, 2019). In addition, Macao government has committed to working to improve physical and social environments to maximize people's potential in functioning. Macao 
has only four hospitals, and the total number of hospital beds are 1600 in public and private sectors. The need for professionalism in nursing care is especially important.

There is a current concern that nursing students do not demonstrate appropriate nursing professionalism in their attitude or functioning in clinical experience (Lipscomb \& Snelling, 2010). Some clinical preceptors also express dissatisfaction with aspects of nursing students performance in the ward (Mirzaei, Oskouie, \& Rafii, 2012). This qualitative study was conducted to explore clinical preceptor views of nursing student functioning in clinical practice settings.

\section{Literature review}

A professional attitude and demeanor is fundamental to professional nursing patient care. Patients can readily sense the nursing staff's attitude as being professional or not. The same is true for nursing students. The historical definition of professionalism includes criteria such as learned theory, knowledge, skill, preparation in the setting, and enforcement of standards of practice for all nurses (Kozier, Erb, \& Olivieri, 1991). Many countries have standards of professional performance that include aspects of ethics, education, quality of practice, and professional practice evaluation such as that in the United States (American Nurses Association, 2010). These standards provide objective guidelines important for accountability to patients, peers, and public. After historical changes in nursing, the criteria for professionalism now also include additional elements, such as autonomy, research participation, and expectations of continuing education (Bayik, Uysal, Artlahan, \& Ozkahraman, 2010; Hisar \& Karadag 2010). Therefore, professionalism is readily assessed and evaluated during the clinical practicum with regard to patient care. Recently, there has been a trend toward enforcing a professional attitude in nursing students in Eastern countries such as Turkey, Korea and Taiwan (Bang et al, 2011; Lin, Wang, Yarbrough, Alfred \& Martin, 2010; Ozcan, Akpinar, \& Ergin, 2012). This trend may have developed because educators have recognized that new nurses are not demonstrating the characteristics of professionalism. 
Therefore, it is necessary to teach nursing students early and often of the need for a professional demeanor during their clinical practicum. Even nursing students who have performed remarkably well in classroom learning assessments and evaluations may have trouble in clinical practice (McGregor, 2007). Most nursing students are novices at providing patient care when they first start their preceptorships. Nevertheless, nursing students need to be informed of their weaknesses and need to know how their practice and skill behaviors are perceived by their clinical preceptors during their mentoring periods. Essential elements for professionalism in nursing students like behaving according to ethical issues, efficient communication, uniform and appearance, on-time during practicum and well-knowledgeable are also necessity (Altiok \& Ustum, 2016, Tanner, 2019). Previous studies have demonstrated that clinical preceptors' views and clinical activities are indispensable means of nursing student growth (Martensson, Engstrom, Mamhidir \& Kristofferzon, 2013). Yamada and Katsumasa (2012) isolated essential roles of clinical nursing instructors that foster proper preparation, patient safety and coordination with faculty.

\section{Study Aim}

The initial motivation was discovering clinical preceptors' perceptions of nursing student behavior during practicum in dimensions such as professionalism, theory, knowledge, nursing skill and communication. The aim is to describe student clinical performance as viewed by clinical preceptors. Findings will document preceptor views and be informative for faculty and students.

\section{Methods}

\section{Design}

A qualitative approach of focused ethnography was used. The design is suitable to describe a distinct issue or shared experience in sub cultures and specific settings (Cruz \& Higginbottom, 2013). Ethnography is useful in studying the cultural issues of interest within and outside of the culture (Burns \& Grove, 2011). Focused ethnography is particularly suited because clinical 
preceptors' views of student clinical performance is a specific issue within a context of a small group of people. A qualitative study is beneficial for obtaining details of a situation, including participants' consciousness, beliefs, and opinions, which are difficult to obtain with other research methods (Corbin \& Strauss, 2008). A purposive sampling (Burns \& Grove, 2011) was used.

\section{Participants}

Interviews with clinical preceptors about their perceptions of nursing student performance in the clinical practicum were the primary data source. The practicum venues include one public and one private hospital, one health-care center, and a nursing home. Eighteen preceptors consented to interviews that were audiotaped for transcription and two additional preceptors consented to interviews with researcher recall written transcripts of their interviews. Informed consent and demographic data were obtained prior to interviews. Researcher notes and field observations at the units were two secondary sources of data used to support interview findings.

\section{Ethical Consideration}

Official permission to conduct the study was approved by the Internal Review Management Board of the Research Committee at the Macao Polytechnic Institute in order to protect the welfare and human rights of participants. Preceptors' participation was voluntary and they were verbally informed about the study aim, design, and their choice to decline participation or end the interview at any point. Written consent was gained prior to interviews. Research rigor included credibility, confirmability, data source triangulation, and research team peer checking.

\section{Data Collection}

The questions for the interviews (Table 1) were developed based on reviews of the literature about issues that clinical preceptors with nursing students (McGregor, 2007; Blackman, Hall \& Darmawan, 2007), the school's clinical practicum evaluation, and student input. The categories of interview questions included professional attitude, knowledge, and skills. 
Table 1: Interview questions

1. How do you perceive the professional attitude of our school's nursing students? Please describe.

2. How about the knowledge of the nursing students? Is it adequate? Please describe.

3. How do you perceive the nursing skills of the students? Please describe how they perform, and give examples.

4. Please discuss the nursing students' communication skills without considering the evaluation sheet. If their communication skills are inadequate, how can the students improve these skills?

5. What are the students' strengths? What comments or suggestions do you have regarding the students' weaknesses?

6. What are your comments/suggestions regarding inadequate student performance with respect to professional attitude, skills, knowledge and communication skills during the practicum?

To obtain responses from those of various wards, all clinical preceptors serving in medical wards, surgical wards, critical care wards, health-care centers and nursing homes were selected to request participation in the study. To have broad hospital representation, at least one clinical preceptor was invited from each ward used for clinical experiences of nursing students in years one through four of the bachelor degree program. The interviews took place immediately after the students had finished the spring semester. At the beginning of each interview, the participant confirmed that the interview could be recorded and were assured of recording confidentiality. The interviews were conducted in Cantonese and recordings were transcribed verbatim then analyzed immediately to capture essential data. Researcher's thoughts and feelings were transcribed at this time as well. Each transcription was de-identified and coded as numbers A01 - A20. 


\section{Data analysis}

A qualitative study traditionally uses deductive and inductive strategies. Corbin and Strauss (2008) emphasized an inductive approach that allows the researchers to validate emerging meaning through continuously interpretation and comparison. The de-identified transcripts were examined using this thematic content analysis. Attributes were identified and grouped based on discovery of commonalities across participants, subthemes were formed by the grouping of similar attributes and number of times they occurred in the interviews, and the theme identification emerged (Corbin \& Strauss, 2008). To achieve acceptable levels of inter-rater reliability in analysis, nurse colleagues independently coded $10 \%$ of the transcripts (Corbin \& Strauss, 2008). Subsequently, an English version of the report was prepared. Additional data analysis was conducted in English to assure accuracy of translation and clarity in nuance of meaning. Data source triangulation with researcher notes and field observations and team peer checking took place. In order to show relationship between theme, subthemes, and attributes clearly, a diagram (Figure 1) portrays data analysis conclusions. Author also mentors nursing students for over ten years. With the author perceptions and clinical preceptors expression, as well as the data analysis, findings were active behavior, having a "heart" during caring, and demonstrating a professional image. Details were written below.

\section{Results}

Of the 20 clinical preceptors interviewed, 19 were female and one was male. Wards represented included medical, medical-surgical, critical care, obstetric/gynecological, pediatric medical-surgical, pediatric critical care, psychiatric, health-care center, and nursing home. Education ranged from BSN through postgraduate degrees. Clinical experience ranged from 6 to over 30 years. Clinical preceptor experience ranged from 2 to 20 years. 
20 clinical preceptors gave their impression after they have done their shift in the ward. Free expression of the 20 clinical preceptors provided much worthwhile content. The content analysis identified one predominant theme: nursing professionalism of students. It was believed by preceptors that if nursing students can understand and satisfactorily demonstrate professionalism, other difficulties that arise during the clinical practicum can be easily solved. The primary theme of professionalism was composed of 3 subthemes: active behaviors, having "heart," and demonstrating a professional image. These three subthemes were each composed of attributes. Details are explained below and portrayed in Figure 1. 
Figure 1: Theme Characteristics of Nursing Student Professionalism

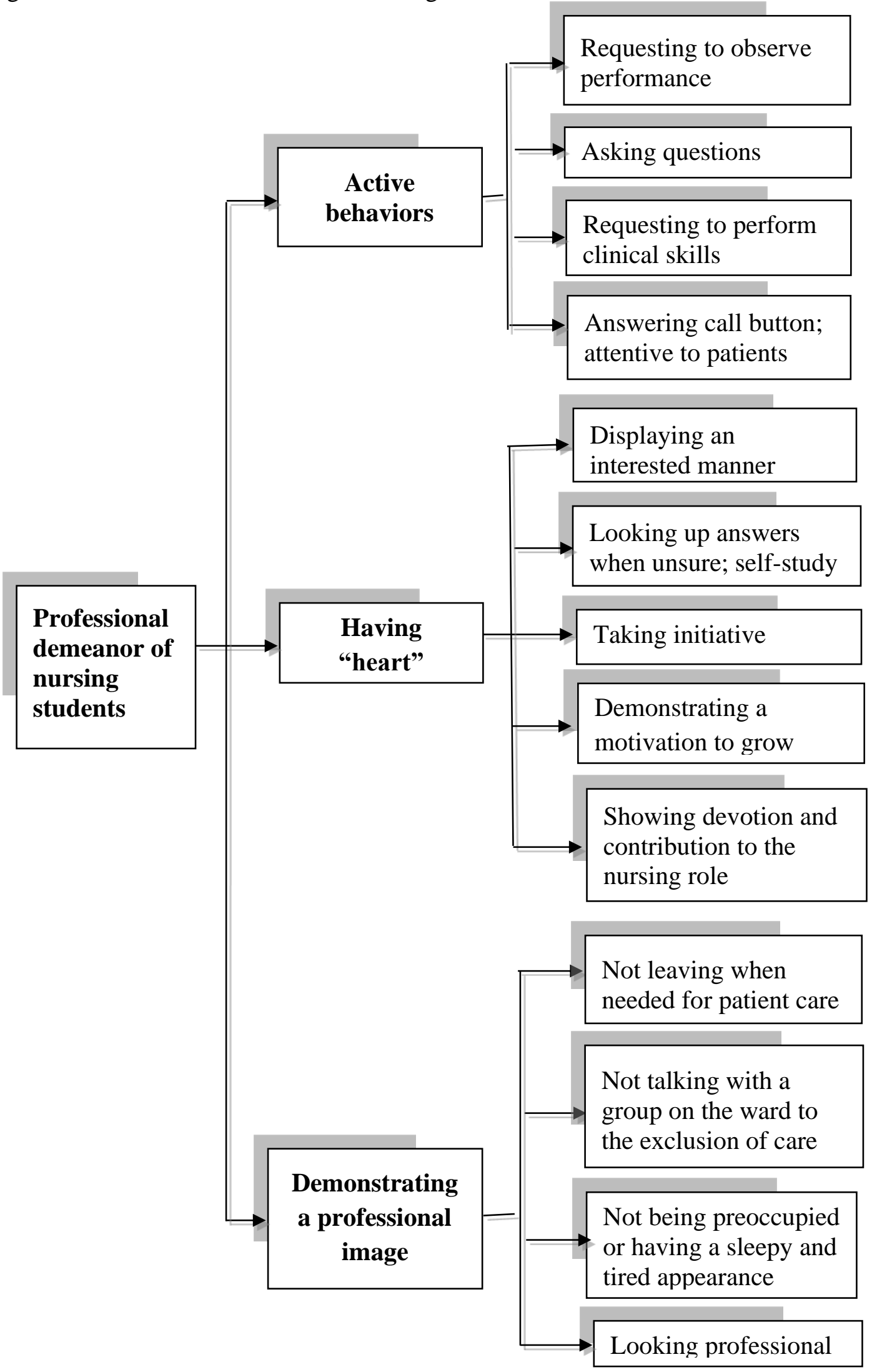


The first subtheme of active behaviors was the most important issue identified by almost all clinical preceptors. Preceptors wanted students to engage in clinical learning actively. This included requesting to observe others' performance whenever a patient treatment was conducted. Asking questions was important when students were confused, rather than pretending that they understood. Also, actively requesting to perform skills such as drawing blood or taking initiative in care such as answering the patient call button requests was felt to demonstrate active behaviors. Being attentive to patients was essential. One preceptor commented:

"Suggest to the nursing students that they can walk faster; don't let the patients wait for a long time. I remember one time when all the nurses had already left to give their shift reports, and the nursing students were still at the nursing counter. Even though I reminded them that it was time for reporting, they still seemed unwilling to listen shift report."

Another example comment shows a lack of active behaviors:

"I don't like them needing to be pushed to observe and participate in skill performance. They need to ask questions and self-assess what they want to learn. They need to set their own goals in our ward. You know, a nurse asked one Year 4 student to observe a central line insertion. The student replied that she had already observed it once, so there was no need. This is not just one or two students behaving like that. A student even refused to perform a Foley catheter insertion. You can't imagine what happens nowadays. I remember when we were nursing students, we had to fight for the chance to perform nursing skills."

One preceptor suggested the following:

“My suggestions for improving the students' professionalism is to instill the spirit of a professional attitude in students during the mentoring process. Teach them to treasure the chance to practice nursing skills and provide safe care. Help them develop a willingness to engage in lifelong education." 
Another preceptor demonstrate an example of 'active behaviour'

"A few students will look up their questions and sources and share with me the following day of practice. A few students even search very recently treatment and medicine for some patients who have chronic illness. Teaching is a kind of active learning, nursing students not only learn from clinical preceptors but also share their interested and theory knowledge with clinical preceptors."

\section{Having "heart"}

Having the "heart" to be a nurse is one of the major subthemes contributing to professionalism or professional demeanor of nursing students. Many clinical preceptors (13 out of 20) agreed that some nursing students do not have the "heart" to become skilled in the nursing profession. Young people might choose to go into nursing because they note the high salaries for nursing jobs even though they do not really love caring for patients. This leads to a perspective of working for pay but not having the motivation to become truly professional. One clinical preceptor noted it is easy to be recruited into the health-care sector by financial motivation. An example of having "heart" is seen in this comment:

"I do not expect Year 1 students to have a strong professional attitude; I just see whether they have the heart to learn such as whether they ask questions, and whether they offer to assist patients with ambulatory difficulties to walk. Students' motivation is the most important element in showing whether they have the heart to be a nurse."

Displaying interest, conducting self-study in order to care, taking initiative, demonstrating a motivation to grow, and actually having a devotion to contribute to nursing role were important attributes of the subtheme, having "heart." As one preceptor shared:

"Students need to search for answers and report back to their preceptors with their findings, showing that they have the "heart" to learn. They should not wait for the preceptor to ask them 
questions; they should look up the answers and report to the preceptor with the answers right away. Doing so may show the preceptors that the students have the "heart" to learn."

It was believed that if students had "heart," they could "overcome difficulties, no matter how hard" but that if they did not, "no matter how easy the work is, you will still not be able to figure it out." Preceptors felt strongly that, "students need to have heart to care for patients, because the patients are sick and not feeling well; the patients are people, not objects." Even if students are quiet in nature, they need to be assertive in clinical work.

\section{Demonstrating a professional image}

Clinical preceptors wanted nursing students to display a professional image in clinical practice. Students must not avoid giving needed patient care. They should not neglect their patients. Also, some students appeared to be very sleepy and tired on the units, some checked their mobile phone messages, and some nursing students grouped together to talk in the hallway. All of these behaviors reflected poor professionalism. Preceptors blamed such incidents on the notion that "young people these days have busy lives and are occupied with many activities each day so do not get enough sleep." Some expressed the lack of professional image in these quotes: "Nowadays, college students work many hours at part-time jobs." "They participate in many activities; they are consumers. They love to have advanced devices like the most recent mobile phone model." The end result of this distraction is lack of focus on nursing care with students not committing themselves to the clinical work or patients. Preceptors thought that strong clinical nurses as role models would be part of the solution for improving student professionalism.

Preceptors thought strong clinical nurses as mentors would motivate students to perform and practice skills and also be the ones to give them more chances to practice. One shared, "If you just tell them (students) to do rounds for the patients, they only do rounds; they do not act like an experienced nurse, chatting with patients and asking about the patients' concerns and problems. 
But when the students see you do it every day they will copy what you do. You will be teaching by action or by example." Another preceptor stated, "I will try to teach them how to project a good image or a professional attitude during the preceptorship process. I will remind them to value the opportunities to practice, emphasize the importance of security in patient care, and possess the will to pursue lifelong education." Preceptors wanted students to look professional in their attire and act professional in their conduct on the unit.

\section{Discussions}

This study has provided an understanding of clinical preceptors' perceptions of nursing students during the nursing education practicum in Macao. The preceptors interviewed for this focused ethnographic study observed that the major performance inadequacy among nursing students during practicum was their lack of professional demeanor. Active behaviors, having "heart," and demonstrating a professional image are the three subthemes of professionalism that were of primary importance to preceptors. Preceptors would like nursing students to be trained in the elements of professionalism as early as possible.

In the view of preceptors, "active behaviors" means that nursing students learn and practice skills without having to be reminded or pushed to do so (Altiok \& Ustum, 2016, Tanner, 2019). Students take initiative. Sometimes even adequate nursing students may need encouragement to be motivated. As noted by Li, An, and Li (2010), some immature students prefer to be guided by and observe demonstrations performed by their educators. They lack the motivation to initiate their own learning of skills and yet demonstration has been shown to be the most effective strategy to improve skills and knowledge (Khan, Ali, Vazir, Barolia, \& Rehan, 2012; Altiok \& Ustum, 2016). Immature students lack self-confidence (Aoyama, Tamura, Ishikawa, Yada \& Miyawaki, 2013). Other Chinese studies imply that self-directed learning readiness and self-efficacy are important factors that influence student performance abilities (Zhao, Guu, Liu, \& Zhang, 2012). 
Therefore, clinical preceptor role modeling continues to be vital (Klunklin et al., 2011; Nouri, Ebadi, Alhani, Rejeh \& Ahmadizadeh, 2013, Phuma-Ngaiyaye, Bvumbwe \& Chipeta, 2017).

As one clinical preceptor stated, students' fear and anxiety need to be considered whenever they arrive on an unfamiliar new ward. Clinical preceptors should provide a detailed explanation to students to help reduce their anxiety and fear (Jamshidi etc, 2016; Pickles, King, \& Belan, 2012). A good relationship of staff with students creates an environment of belonging and fosters learning behaviors essential for positive clinical experiences (Fisher \& King, 2010; Levett-Jones, Lathean, Higgins, \& McMillan, 2009). One study highlighted nursing student readiness for self-directed learning (Klunklin, Nongkran, Acharaporn \& Turale, 2010) so this initiative can be promoted.

Clinical preceptors often preferred nursing students to be observant of patient needs and actively "offer assistance" even with those not specifically under their care. One clinical preceptor unhappily recounted nurses being busy rescuing another patient and a nursing student lacked the initiative to assist other patients with lesser needs. Nursing work is a team job. If students have "heart," they will "devote and contribute" their knowledge and skills.

Skorupski \& Rea (2006) conducted a study of 180 patients, asking them about their image of a professional nurse. Most of the patients preferred nurses to have neat, uniforms. Patients understand that nursing students lack experience, knowledge and skills, but they should at least present the basic components of a professional image such as being neat, tidy and crisp-looking, rather than displaying a "sleepy look." Therefore, nursing students should wear professional attire, pay attention to their nonverbal expressions, and be attentive in their care and professional work. Image is the first thing that patients notice about nurses and other team colleagues. A tidy and neat uniform is the basic standard for providing patient care in the ward during clinical practicum for nursing students in all parts of Chinese society. Additionally, neat hair is considered important both for a good appearance and to avoid contamination when providing bedside care. In traditional 
Chinese culture, wearing the proper, standard uniform to create a good first impression when meeting others is most important; behavior and performance are second in importance.

It is common knowledge but nevertheless important to note that better clinical education leads nursing students to have better critical thinking skills and better theoretical knowledge consolidation so they can provide a better quality of care. Nursing students in any type of nursing program need to learn and practice patient care in acute-care hospitals and non-acute community health-care settings. Consistent with one study, this study found that motivational process toward professionalism is an important aspect of clinical education (Hanifi, Parvizy \& Joolaee, 2013).

Nursing professional demeanor of students including active behaviors, having "heart," and demonstrating a professional image is important no matter where nursing students serve during their four years of clinical practicum. Nursing schools worldwide support training in professionalism during the basic through final nursing courses. Sharif \& Masoumi (2005) claimed that clinical preceptors do not just assist nursing students to grow in professional standard, but also act as a major role-model in areas such as self-confidence, working independence, and developing competency. From this study, clinical preceptors would like students to strengthen professional demeanor by increasing their active nursing behaviors, having a "heart" to grow in their role, and demonstrating a professional image.

Linking of study findings to other theoretical concepts is valuable. Carlson (2013) uses symbolic interactionism (SI) theory with a large ethnographic study about clinical preceptorship. Identifying core principles of SI to include meaning, language, and thought, Carlson deftly links principles with the vital relationship of preceptors and students. We suggest that the theoretical application of SI as well as Carlson's application to preceptors can also be applied to the nursing students. Our study findings could well be interpreted similarly. 
The study shows valuable insights into the way that the clinical preceptors perceive nursing students during practicum in a predominantly Chinese nursing setting. Uniquely only one primary theme was highlighted so this quality of professionalism is likely to be important across cultures. The study design of focused ethnography, is especially useful for gaining insight into a localized culture group. Limitations with both the design and the purposive sampling exist and may reduce generalization of findings to other preceptorships, nursing programs, countries, or culture groups.

\section{Conclusion}

Preceptors wanted students to actively and attentively perform nursing skills, display the desire for and actions of learning, and to demonstrate professionalism in conduct and appearance. Respecting the job, being willing to grow and advance, maintaining cheerful optimism and a desire to be helpful when learning new skills, valuing others' opinions, searching for new knowledge, respecting patients, cooperating with other members of the health-care team, and being accepting of different backgrounds are some of the elements that contribute to a professional demeanor. Also avoiding unprofessional qualities is important for nursing students in clinical experiences. Nursing students need to rotate through a variety of wards to fulfill the curricular requirements to pass clinical practicum. Yet, students are not always aware of what clinical preceptors expect.

Learning about the clinical preceptors' perceptions gives nursing students a better understanding of what is expected of them. The importance of clinical education for nursing students cannot be underestimated. Professionalism makes a difference in clinical learning. This study reveals insight into the importance of professional demeanor of nursing students during clinical practice. 


\section{Acknowledgements}

The authors sincerely express appreciation to study participants who generously provided their time, invaluable contribution, and trust in the interviews. The authors would like to thank the Board Of Management of Macao Polytechnic Institute for providing funding for this study (RP/ESS-04/2012).

\section{References}

American Nurses Association: Nursing: Scope and standards of practice, ed 2, Silver Springs, MD, 2010, The Association. https://doi.org/10.1111/nhs.12066

Aoyama, M., Tamura, Y., Ishikawa, Y., Yada, M. \& Miyawaki, I. (2013), Confidence-weighted testing: A descriptive study of Japanese nursing students. Nursing \& Health Sciences, 15(4), 504-509.

Altiok, H. O. \& Ustun, B. (2016). Meaning of Professionalism in Nursing Students. American International Journal of Social Science, 3(6), 48-60.

Bang, K. S., Kang, J. H., Jun, M. H., Kim, H. S. Son, H. M., Yu, S. J., Kwon, M. K., \& Kim, J. S (2011). Professional values in Korean undergraduate nursing students. Nurse Educ. Today, 31(1), 72-75. https://doi.org/10.1016/j.nedt.2010.03.019

Bayik, A. T., Uysal, A, Artlahan, A, \& Ozkahraman, S. (2010). Barriers to research utilization scale: psychometric properties of the Turkish version. Journal of Advanced Nursing. 66(2), 456-464. https://doi.org/10.1111/j.1365-2648.2009.05162.x

Benner, P., Sutphen, M., Leonard, V., \& Day, L. (2009). Educating nurses: a call for radical transformation. San Francisco, CA: Jossey-Bass. 
Blackman, I., Hall, M., \& Darmawan, I. G. N. (2007). Undergraduate nurse variables that predict academic achievement and clinical competence in nursing. International Education Journal, 8(2), 222-236.

Botti, M. \& Reeve, R. (2003), Role of knowledge \& ability in student nurses' clinical decisionmaking. Nursing \& Health Sciences, 5(1), 39-49. https://doi.org/10.1046/j.14422018.2003.00133.x

Burns, N. \& Grove, S. K. (2011). Understanding nursing research: building and evidence-based practice $\left(5^{\text {th }}\right.$ ed). Maryland Heights, MO: Elsevier Saunders.

Carlson, E. (2013). Percepting and symbolic interactionism- a theoretical look at preceptorship during clinical practice. Journal of Advanced Nursing, 69(2), 457-464. https://doi.org/10.1111/j.1365-2648.2012.06047.x

Corbin, J. \& Strauss, A. (2008). Basics of Qualitative Research (2nd ed). Los Angeles, CA: Sage Publication.

Cruz, E. V. \& Higginbottom, G. (2013). The use of focused ethnography in nursing research. Nurse Researcher, 20(4), 36-43. https://doi.org/10.7748/nr2013.03.20.4.36.e305

Hanifi, N., Parvizy, S. \& Joolaee, S. (2013), Motivational journey of Iranian bachelor of nursing students during clinical education: a grounded theory study. Nursing \& Health Sciences, 15(3), 340-345. https://doi.org/10.1111/nhs.12041

Health Statistics (2019). Government of Macao special administrative region. Available at: https://www.dsec.gov.mo/Statistic.aspx?lang=en-US\&NodeGuid=251baebb-6e5b-44528ad1-7768eafc99ed.

Henderson, A. \& Tyler, S. (2011). Facilitating learning in clinical practice: Evaluation of a trial of a supervisor of clinical education role. Nurse Education in Practice, 11(5), 288-292. https://doi.org/10.1016/j.nepr.2011.01.003 
Hickey, M. T. (2010). Baccualaureate nursing graduates' perceptions of their clinical instructional experiences and preparation for practice. Journal of Professional Nursing, 26(1), 35-41. https://doi.org/10.1016/j.profnurs.2009.03.001

Hisar, F. \& Karadag, A. (2010). Determining the professional behaviour of nurse executives. International Journal of Nursing Practice, 16(4), 335-341. https://doi.org/10.1111/j.1440172X.2010.01849.x

Jamshidi,N., Molazem, Z., Sharif, F., Torabizadeh,C. \& Kalyani., M. N. (2016). The challenges of nursing ctudents in the clinical learning environment: a qualitative study. The Scientific World Journal, Article ID 1846178, 1-7. https://doi.org/10.1155/2016/1846178

Karagozoglu, S. (2008). Level of autonomy of Turkish students in the final year of university baccalaureate degree in health related fields. Nursing Outlook, 56(2), 70-77. https://doi.org/10.1016/j.outlook.2007.11.002

Khan, B., Ali, F., Vazir, N., Barolia, R., \& Rehan, S. (2012). Students' perceptions of clinical teaching and learning strategies: A Pakistani perspective. Nurse Education Today, 32(1), 85-90. https://doi.org/10.1016/j.nedt.2011.01.016

Klunklin, A., Nongkran, V., Acharaporn, S, \& Turale, S. (2010). Readiness for self-directed learning among nursing students in Thailand. Nursing \& Health Sciences, 12(2), 177-181. https://doi.org/10.1111/j.1442-2018.2010.00515.x

Klunklin, A., Sawasdisingha, P., Viseskul, N., Funashima, N., Kameoka, T., Nomoto, Y., \& Nakayama, T. (2011). Role model behaviors of nursing faculty members in Thailand. Nursing \& Health Sciences, 13(1), 84-87. https://doi.org/10.1111/j.14422018.2011.00585.x

Kozier, B., Erb, G., \& Olivieri, R. (1991). Fundamentals of nursing: concepts, process and practice $4^{\text {th }}$ ed. Addison-Wesley Publishing Company; California, pp. 1-52, 1991. 
Kragelund, L. (2011). Student nurses' learning processes in interaction with psychiatric patients; a qualitative investigation. Nurse Education in Practice, 11(4), 260-267. https://doi.org/10.1016/j.nepr.2010.11.019

Leong, C.S.U., Xing, Z. H., \& Wong, F.W.F. (2013). Professional Nursing Education Development: A Transitional Milestone from Diploma Level to Graduate Level in Macao. Education, 3(6): 279-286.

Levett-Jones, T., Lathean, J., Higgins, I., \& McMillan, M. (2009). Staff-student relationship and their impact on nursing students' belongings and learning. Journal of Advanced Nursing, 65(2), 316-324. https://doi.org/10.1111/j.1365-2648.2008.04865.x

Li, L. J., An, L. B., \& Li, W. T. (2010). Nursing students' self-directed learning. Chinese Gen. Nurs., 8(5), 1205-1206.

Lin, Y. H., Wang, L.S., Yarbrough, S., Alfred, D., \& Martin P. (2010). Changes in Taiwanese nursing student values during the educational experience. Nuring Ethics, 17(5), 646-654. https://doi.org/10.1177/0969733010373011

Lipscomb, M., \& Snelling, P.C. (2010). Student nurse absenteeism in higher education: An argument against enforced attendance. Nurse Education Today, 30(6), 573-578. https://doi.org/10.1016/j.nedt.2009.12.003

Loke, A. J. T., \& Chow, F. L. W. (2007). Learning partnership-the experience of peer tutoring among nursing students: A qualitative study. International Journal of Nursing Studies, 44, 237-244. https://doi.org/10.1016/j.ijnurstu.2005.11.028

Martensson, A., Engstrom, M., Mamhidir, A. G., \& Kristofferzon, M. L. (2013). What are the structural conditions of importance preceptors' performance? Nurse Education Today, 33(5), 444-449. https://doi.org/10.1016/j.nedt.2012.04.015 
McGregor, A. (2007). Academic success, clinical failure: Struggling practices of a failing student. Journal of Nursing Education, 46(11), 504-511. https://doi.org/10.3928/0148483420071101-05

Megel, M. E., Nelson, A. E., Black, J., Vogel, J., \& Uphoff, M. (2013). A comparision of student and faculty perceptions of clinical post-conference learning environment. Nurse Educ. Today, 33(5), 525-529. https://doi.org/10.1016/j.nedt.2011.11.021

Mirzaei, T., Oskouie, F., \& Rafii, F. (2012). Nursing students' time management, reducing stress and gaining satisfaction: A ground theory study. Nursing \& Health Sciences, 14(1), 46-51. https://doi.org/10.1111/j.1442-2018.2011.00661.x

Nouri, J. M., Ebadi, A., Alhani, F., Rejeh, N. \& Ahmadizadeh, M. J. (2013), Qualitative study of humanization-based nursing education focused on role modeling by instructors. Nursing \& Health Sciences, 15(1), 137-143. https://doi.org/10.1111/j.1442-2018.2012.00732.x

Ohrling, K. \& Hallberg, I. R. (2000). Student nurses' lived experience of preceptorship, part I - in relation to learning. International Journal of Nursing Studies, 37(1), 13-27. https://doi.org/10.1016/S0020-7489(99)00054-1

Ozcan, M., Akpinar, A., \& Ergin, A. (2012). Personal and professional values grading among $\begin{array}{llll}\text { midwifery } \quad \text { students. } \quad \text { Nursing } \quad \text { Ethics, } & \text { 19(3), }\end{array}$ https://doi.org/10.1177/0969733011433921

Phuma-Ngaiyaye, E., Bvumbwe, T. \& Chipeta, M. C. (2017). Using preceptors to improve nursing students' clinical learning outcomes: a Malawian students' perspective. International Journal of Nursing Sciences, 4, 164-168. https://doi.org/10.1016/j.ijnss.2017.03.001

Pickles, D., King, L., \& Belan, I. (2012). Undergraduate nursing students' attitudes towards caring for people with HIV/AIDS. Nurse Educ Today, 32, 15-20. https://doi.org/10.1016/j.nedt.2011.01.008 
Sharif, F. \& Masoumi, S. (2005). A qualitative study of nursing student experiences of clinical practice. BMC Nursing, 4(6), 1-7. https://doi.org/10.1186/1472-6955-4-6

Skorupski, V. J., Rea, R. E. (2006). Patients' perceptions of today's nursing attire: exploring dual images. Journal of Nursing Administration, 36(9), 393-401. https://doi.org/10.1097/00005110-200609000-00005

Tanner, M. (2019). The Characteristics of a Professional Nursing Student, John Hopkins, school of Nursing, retrived at: https://minoritynurse.com/the-characteristics-of-a-professionalnursing-student/.

Wolff, A. C., Regan, S., Pesut, B., \& Black, J. (2010). Ready for what? An exploration of the meaning of new graduate nurses' readiness for practice. Int. J. Nurs. Educ. Scholarsh., 7(1), 1-14. https://doi.org/10.2202/1548-923X.1827

Yamada, S. \& Ota, K. (2012), Essential roles of clinical nurse instructors in Japan: A Delphi study. Nursing \& Health Sciences, 14(2), 229-237. https://doi.org/10.1111/j.14422018.2012.00683.x

Zhao, F. F., Guu, Y. H., Liu, W. W., \& Zhang, F. (2012). The study on the relationship between nursing students' self-efficacy and self-directed learning. J. Nurs. Training (Chinese), 25(6), 519-522. 